\title{
ACRF Instrumentation Status: New, Current, and Future
}

February 2007

James Liljegren

ACRF Instrument Team Coordinator

Work supported by the U.S. Department of Energy, Office of Science, Office of Biological and Environmental Research 


\section{Summary}

The purpose of this report is to provide a concise but comprehensive overview of Atmospheric Radiation Measurement Program Climate Research Facility instrumentation status. The report is divided into four sections: (1) new instrumentation in the process of being acquired and deployed, (2) existing instrumentation and progress on improvements or upgrades, (3) proposed future instrumentation, and (4) Small Business Innovation Research instrument development. New information is highlighted in blue text. 


\section{Contents}

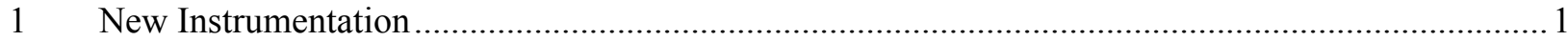

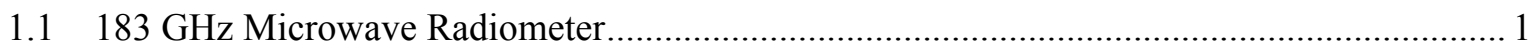

1.2 High-Frequency Microwave Radiometer ........................................................................... 1

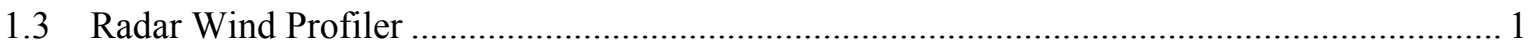

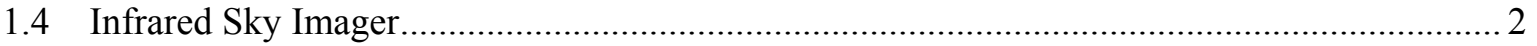

1.5 Add Multi-Filter Radiometers to Cessna 206 ..................................................................... 2

1.6 DigiCORA-III for Manus, Nauru ..................................................................................... 2

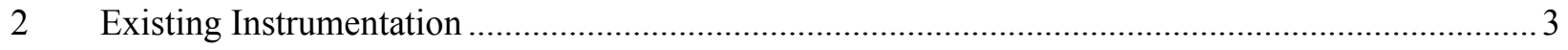

2.1 Atmospherically Emitted Radiance Interferometer ........................................................ 3

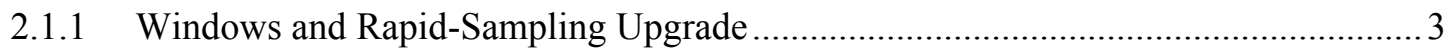

2.2 Aerosol Observing System ........................................................................................... 3

2.2.1 Reconfigure Southern Great Plains Aerosol Observing System ................................ 4

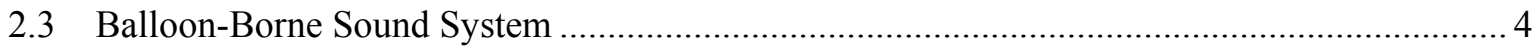

2.3.1 Make Atmospheric Radiation Measurement Program-Barrow Soundings Available to the Global Telecommunication System ............................................... 4

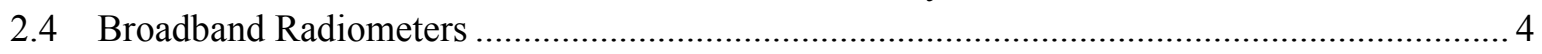

2.4.1 Pyrgeometer Calibration Improvements ............................................................ 5

2.4.2 Radiometer Calibration Facility Data Acquisition System Replacement ....................5

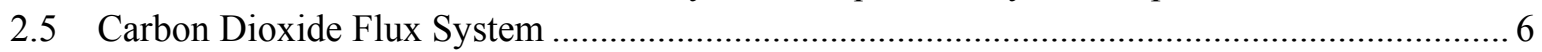

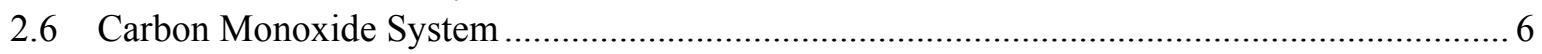

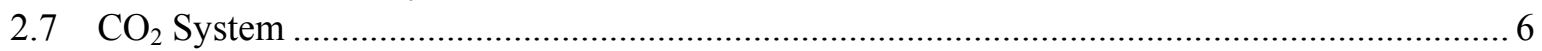

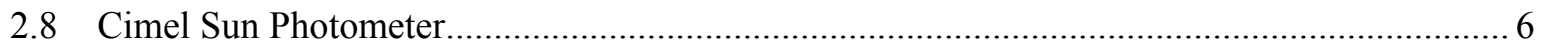

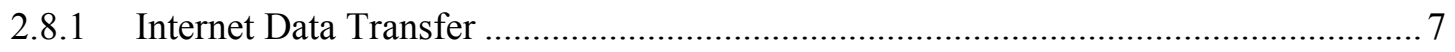

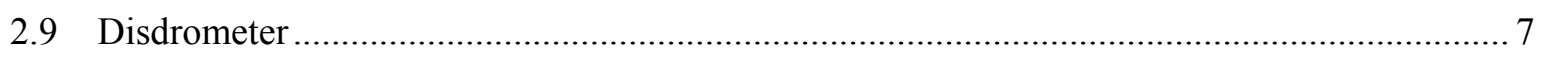

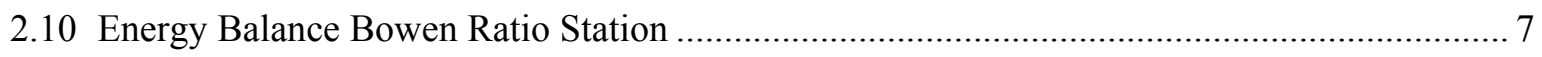

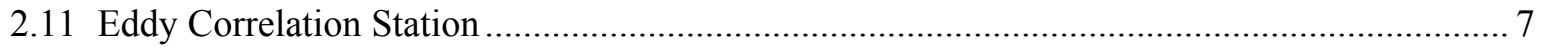

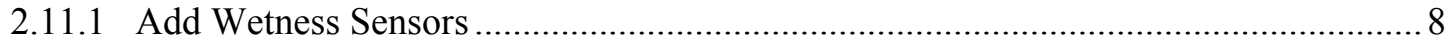

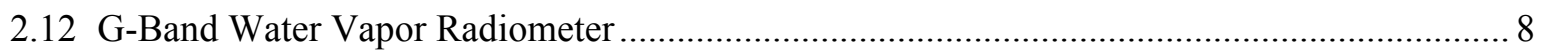

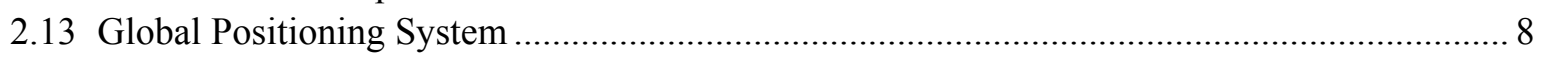

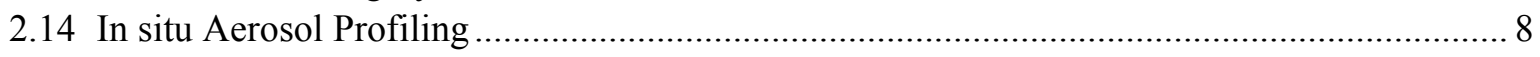

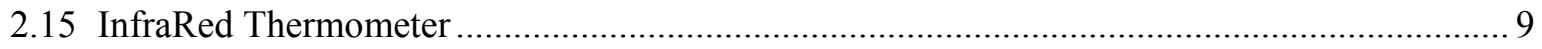

2.16 Multi-Filter Rotating Shadowband Radiometer and Related Systems ................................. 9

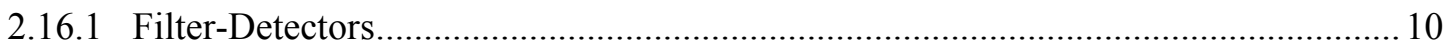

2.16.2 Multi-Filter Rotating Shadowband Radiometer Calibration and Data Processing

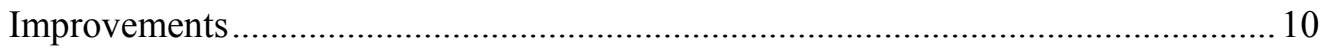

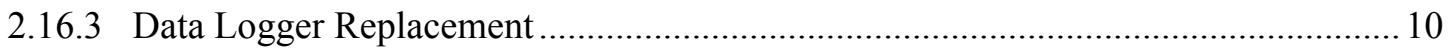

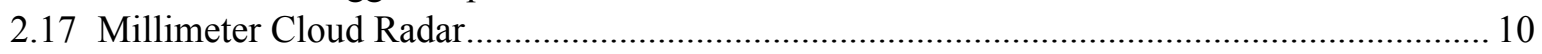

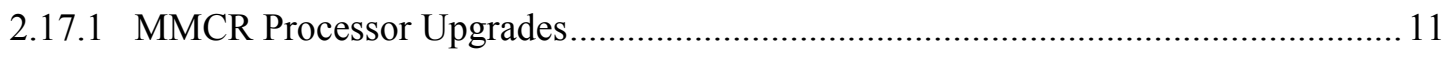

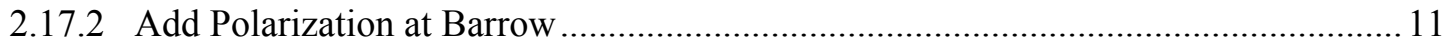

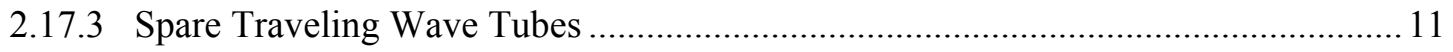

2.17.4 Millimeter Wave Cloud Radar Spectra Processing ................................................... 11

2.17.5 Refurbish Millimeter Wave Cloud Radar Antennas .................................................... 11

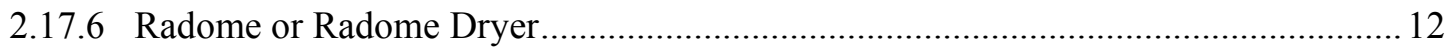




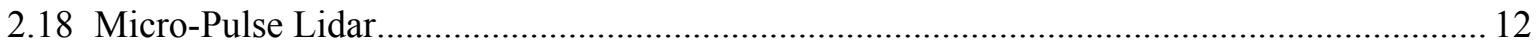

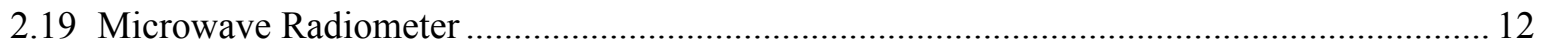

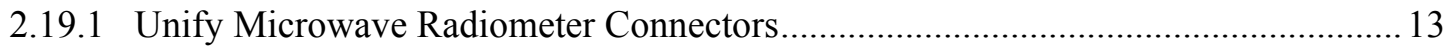

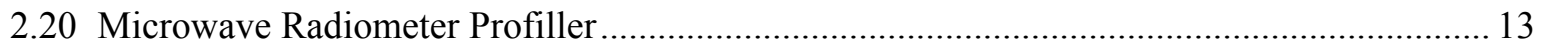

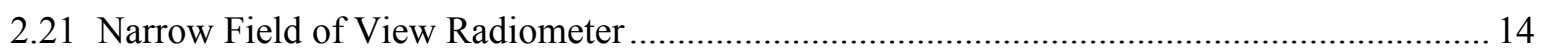

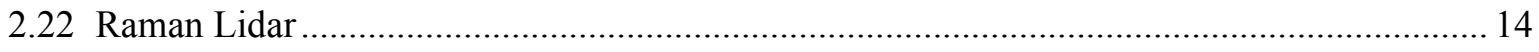

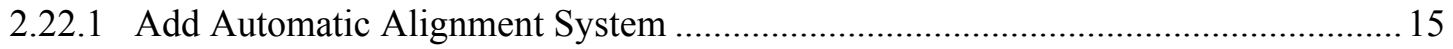

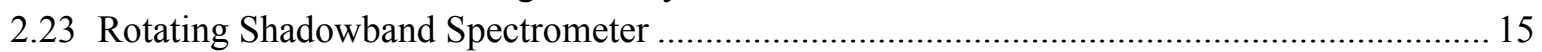

2.24 Radar Wind Profiler - $915 \mathrm{MHz}$..................................................................................... 15

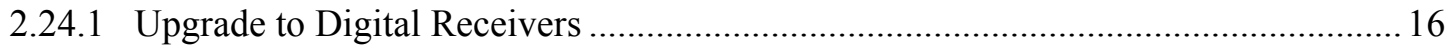

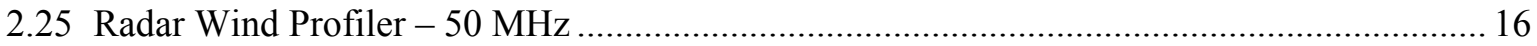

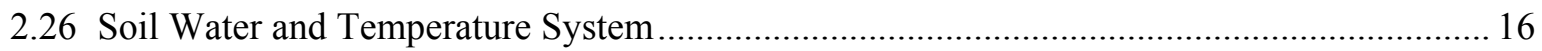

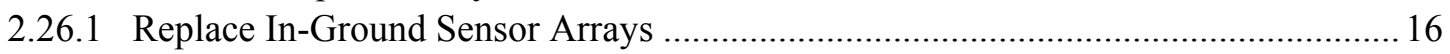

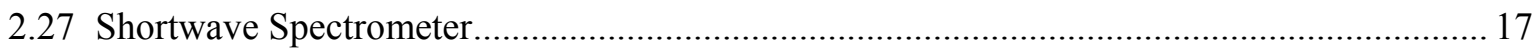

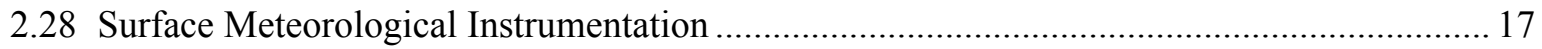

2.28.1 Develop Dynamic Rain Gauge Calibration Facility ............................................... 17

2.28.2 Upgrade T/RH Probes and Wind Sensors for NSA Met Systems .............................. 17

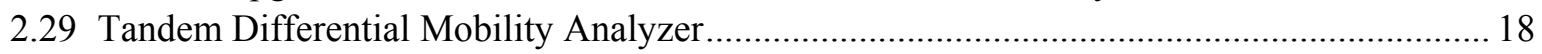

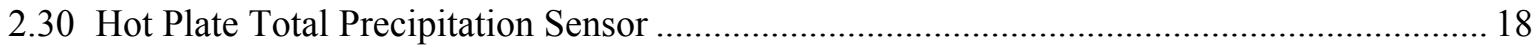

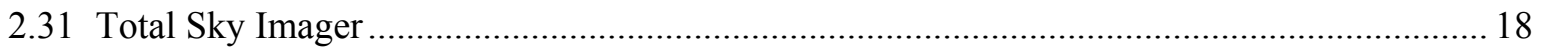

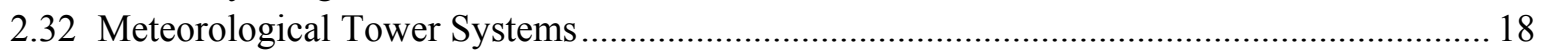

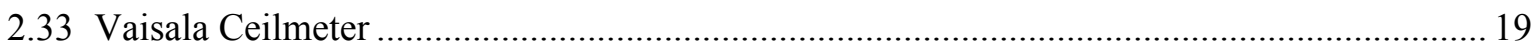

2.34 W-band Atmospheric Radiation Measurement Program Cloud Radar ................................ 19

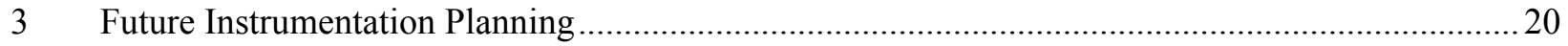

3.1 Atmospheric Radiation Measurement Program Volume-Imaging Array .............................. 20

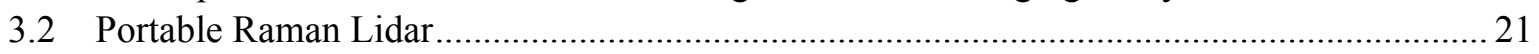

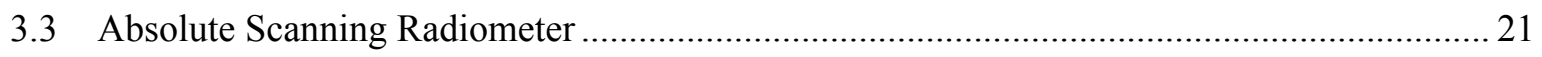

3.4 High-Resolution Oxygen A-Band and Water-Band Spectrometer..................................... 21

3.5 Rotating Shadowband Spectrometer Overhaul …............................................................. 21

3.6 Add 1.6 $\mu \mathrm{m}$ Channel to Multi-Filter Rotating Shadowband Radiometer and

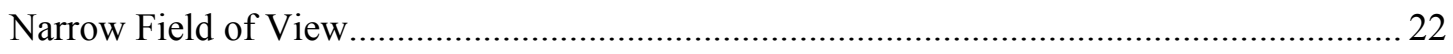

3.7 Aerosol Particle Sizing Spectrometer to Replace Optical Particle Counter at

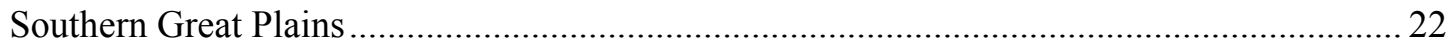

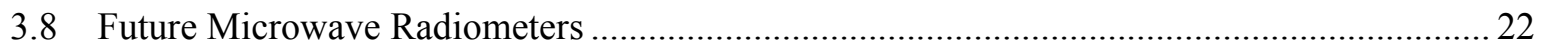

3.9 Modified Muti-Filter Rotating Shadowband Radiometer for Liquid Water Path ................. 22

3.10 Infrared Thermometers for the Southern Great Plains Extended Facility Sites .................... 23

$4 \quad$ Small Business Innovation Research ................................................................................... 24

4.1 Eye-Safe Ultraviolet Backscatter Lidar for Detection of Sub-visual Cirrus ......................... 24

4.2 Instrumentation for Remotely Sensing Aerosol Optical Properties -

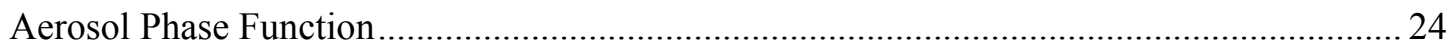

4.3 Unmanned Aerospace Vehicle-Suitable Cloud Radar........................................................... 24

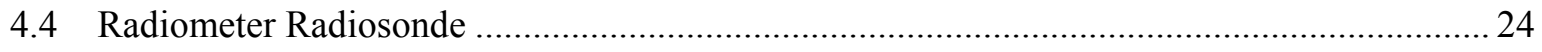

4.5 In situ Measurement of Cloud Properties with Large Sample Volumes .............................. 25 


\section{New Instrumentation}

\section{$1.1 \quad 183 \mathrm{GHz}$ Microwave Radiometer}

Radiometrics Corporation has proposed to deploy at North Slope of Alaska (NSA)-Barrow a new $183 \mathrm{GHz}$ microwave radiometer that they have developed under a U.S. Department of Energy (DOE) Small Business Innovation Research (SBIR) grant (ECO-00609).

STATUS - The radiometer has been shipped to Barrow to participate in the Radiative Heating in Underexplored Bands Campaign (RHUBC). The data will not be ingested but will be available from the intensive operational period (IOP) section of the Atmospheric Radiation Measurement (ARM) Program Archive.

\subsection{High-Frequency $(90 / 150 \mathrm{GHz})$ Microwave Radiometer}

Mentor: Maria Cadeddu, Argonne National Laboratory

In response to the need for greater sensitivity (and therefore higher frequency) microwave channels to more accurately measure liquid water paths in thin clouds than the current $23.8 / 31.4 \mathrm{GHz}$ instruments permit, a new High-Frequency Microwave Radiometer (MWRHF) has been acquired, and is currently deployed at Southern Great Plains (SGP) (ECO-00491).

STATUS - Ingest development for the MWRHF has been completed. Data are available from the ARM Archive back to November 2006 (sgpmwrhfC1.b1). Deployment of the MWRHF to the NSA-Barrow site has been delayed due to funding limitations associated with the Continuing Resolution. A second instrument will be deployed with the ARM Mobile Facility (AMF) at Heselbach, Germany in late April 2007.

\subsection{Radar Wind Profiler}

Mentor: Rich Coulter, Argonne National Laboratory

A 4-panel $1290 \mathrm{MHz}$ radar wind profiler (RWP) has been ordered from Vaisala for the 2007 AMF deployment in Germany. An operating frequency of $1290 \mathrm{MHz}$ was selected to match EU and other global frequency allocations for boundary layer radar profilers (ECO-00513). In July 2006 the Federal Aviation Administration denied a request for a license to operate the new RWP at the SGP for testing prior to the AMF deployment to Germany in 2007.

STATUS - The new RWP has arrived at the AMF site at Heselbach, Germany. 


\subsection{Infrared Sky Imager}

Mentor: Vic Morris, Pacific Northwest National Laboratory

An infrared (IR) sky imager from Blue Sky Imaging (http://www.aas.org/career/bluesky.html) was deployed at SGP in September 2005 to provide nighttime cloud cover measurements (ECO-00429). Problems with moisture infiltration of the imager necessitated its return to the manufacturer for repair/revision in October 2005. The unit was returned to SGP in late June 2006 and returned to service in August 2006.

STATUS - In late January SGP technicians resolved hardware problems and restored the IRSI to operation. Software modifications by the manufacturer have corrected the image mask problem, which has permitted cloud fraction to be derived from the images. In February Vic Morris conducted a comparison of cloud fractions from the IRSI and the total sky imager (TSI). The comparisons indicate the IRSI is still not producing correct values. In March Vic plans to present the results of the comparison at the ARM Science Team Meeting.

\subsection{Add Multi-Filter Radiometers to Cessna 206 (In situ Aerosol Profiling aircraft)}

Currently, spectral albedo measurements are only possible at the SGP central facility using downward facing Multi-Filter Radiometers (MFR) on the 25-m level of the $60-\mathrm{m}$ tower over a wheat field, and on a 10-m tower over the adjoining pasture. By adding a MFR to the Cessna 206 used for the In situ Aerosol Profile (IAP), routine measurements of surface spectral albedo could be acquired over a broader area around the SGP central facility (ECO-00584).

STATUS - A contract has been awarded to mount the MFR in the wing-tip extensions.

\subsection{DigiCORA-III for Manus, Nauru}

Mentor: Barry Lesht, Argonne National Laboratory

The digiCORA is the ground station for the Vaisala balloon borne sounding system. In FY 2003-2004 new digiCORA-III systems were acquired and deployed at SGP-Central Facility (CF), NSA-Barrow, and AMF as the primary ground station for those sites. For reliability and compatibility reasons it is necessary to replace the digiCORA-II systems at Manus and Nauru with the new digiCORA-III systems (ECO-00598).

STATUS - A new digiCORA-III will be installed on Nauru in April. A new digiCORA-III will be installed on Manus in June, after the necessary antenna upgrade kit is acquired. 


\section{Existing Instrumentation}

This section describes the current status of the existing instrumentation, including any upgrades planned or in progress. The information is abstracted primarily from the Instrument Mentor Monthly Summary reports (available from the instrument web pages) and from ECO status updates.

\subsection{Atmospherically Emitted Radiance Interferometer}

Mentor: Dave Turner, Space Science and Engineering Center, University of Wisconsin

SGP - Both the OS/2-based atmospheric emitted radiance interferometer (AERI) and the Windows XPbased AERI are operating nominally.

NSA - This Windows XP-based AERI is operating nominally. RFI continues to be a problem at this site. Efforts to try to reduce the RFI noise in the NSA-C1 data via post-processing of the raw data are on going.

TWP (Darwin) - This AERI is out of service for repair, reintegration, realignment, and recalibration. It is expected to return to service in March, upgraded for Windows XP and rapid sampling.

TWP (Nauru) - This Windows XP-based AERI is operating nominally.

AMF - Currently shut down, awaiting shipment to Germany with the AMF.

Spare - The spare ER-AERI is being repaired and will be redeployed at Barrow in support of the RHUBC. The OS/2-based spare AERI at Space Science and Engineering Center would need to have the aging laser replaced in its interferometer before it could be sent to Darwin as a replacement.

\subsubsection{Windows and Rapid-Sampling Upgrade}

Migration of the AERI software from OS/2 Warp to Windows XP and related computer hardware modernization to enable rapid sampling of the IR spectrum at 10-s intervals was begun in FY 2004 (ECO00286). Upgraded AERI systems are currently operational at SGP, NSA-Burrow, and Tropical Western Pacific (TWP)-Nauru.

STATUS - Substantial progress has been made in preparing an upgraded (Windows) electronics rack that will be soon shipped to Germany to replace the old OS/2 electronics rack used with the AMF AERI system.

\subsection{Aerosol Observing System}

Mentor: John Ogren and Anne Jefferson, NOAA/ESRL/GMD

The repaired CPC (Condensation Particle Counter) was returned to SGP on 23 February. The NOAA loaner will be returned to the mentor. 


\subsubsection{Reconfigure Southern Great Plains Aerosol Observing System}

The aerosol observing system (AOS) at SGP will be reconfigured to have similar components and data acquisition system as the aerosol systems for AMF, NSA, and the IAP aircraft measurements over the SGP (ECO-00569). This work is scheduled for 13 May - 1 June 2007.

\subsection{Balloon-Borne Sound System}

Mentor: Barry Lesht, Argonne National Laboratory

NSA and SGP ascent rates continue to be somewhat lower than at the other sites. Because of an international shortage of helium, in October 2006 we began conservation measures that included underfilling the balloons at SGP, so they again had lower ascent rates. The median ascent rate at SGP was $3.5 \mathrm{~m} / \mathrm{s}$. The median duration of NIM soundings was about 4000s. NSA and TWP/C1 soundings had median durations of about 5800 s.

In PIF P070123.1 Barry reports "the near-surface relative humidity (RH) values in the Barrow soundings have been strange. Jumps of several percent between the surface RH value and the first RH value reported after launch are not uncommon. These jumps seem to occur when the surface temperature is low $\left(\sim<-20^{\circ} \mathrm{C}\right)$. I've looked at several raw data files associated with some of these cases and it appears to me as though the RH heating cycle is too short to allow the RH sensors to equilibrate. At this point, this is only an impression based on examination of a few files. I have contacted Vaisala about this."

\subsubsection{Make Atmospheric Radiation Measurement Program-Barrow Soundings Available to the Global Telecommunication System}

January 2007 - Soundings from SGP and NSA (Barrow) are now available to the global telecommunications system (GTS). Soundings from TWP (Manus and Nauru) will also be available to the GTS once the new DigiCORA-III systems are installed and operational there.

\subsection{Broadband Radiometers (SIRS, SKYRAD, GNDRAD, BRS)}

Mentor: Tom Stoffel, National Renewable Energy Laboratory

SIRS (24@SGP) and BRS (1@SGP) - More than 92\% of the shortwave and 100\% of the longwave data passed automated data quality tests. Some sites were affected by severe winter weather conditions across the SGP domain in January.

SKYRAD/GNDRAD (3@TWP, 2@NSA, 1@NIM)-99\% of the shortwave and 100\% of the longwave data passed automated data quality tests.

At all sites small (approximately 20 to 50 Watts per square meter) discrepancies and intermittent data inconsistencies among coincident measurements of 1-minute averaged global, direct, and diffuse broadband irradiances continue. Clear-sky discrepancies are generally limited to early morning and late afternoon when the solar zenith angle is greater than 80 degrees. Measured global is generally less than the summed direct and diffuse. Similar discrepancies occur during partly cloudy conditions during any daylight period. The sources of these apparent discrepancies can be attributed to radiometer measurement characteristics. Angular response: variation of 5 calibration coefficients, termed Responsivity (Rs), with 
solar zenith angle $[\operatorname{Rs}(Z)]$; time constant: varying time response characteristics of thermopile-based instruments; and, thermal offset errors: effects of infrared (sky) radiation on the pyranometer output signal. Each of these measurement issues remains under study.

\subsubsection{Pyrgeometer Calibration Improvements}

Tom Stoffel and Ibrahim Reda have initiated an investigation into the source of the bias in the ARM Climate Research Facility (ACRF) pyrgeometer blackbody calibration system. Once the source of the bias is determined and corrected a careful validation of the system and a comparison of pyrgreometers calibrated with this and other systems will be conducted (ECO-00559).

At blackbody temperatures less than $-20^{\circ} \mathrm{C}$, the Dow Corning 200 fluid viscosity increases, which inhibits mixing and results in a temperature gradient of 1.5 to $2.0^{\circ} \mathrm{C}$ from the base to the top of the hemispherical blackbody. A new set of fluid dispersion manifolds (perforated annuli) has been developed to reduce the temperature gradients in the blackbody. Additionally, a replacement fluid with better low-temperature (viscosity) characteristics has been identified. Two five-gallon containers of this fluid will be acquired for evaluation at National Renewable Energy Laborary (NREL). Pyrgeometers calibrated using the new manifold and fluid will be compared with pyrgeometers having calibrations traceable to the World Infrared Standard Group (WISG) and with pyrgeometers calibrated by NOAA/GMD.

January 2007 - Acquisition of the replacement cooling fluid is on hold due to funding restrictions associated with the Continuing Resolution.

STATUS - Craig Webb and Ibrahim Reda completed outdoor pyrgeometer characterization data collection from the Radiometer Calibration Facility at SGP. Reda completed data analyses and with Tom Stoffel, prepared a poster for Science Team Meeting. Results show seven precision infrared radiometers (PIRs) agree to better than $\pm 1.5 \mathrm{~W} / \mathrm{m}^{2}$ with respect to the interim WISG under all sky conditions and during daytime and nighttime. This compares with $-2.5 \mathrm{~W} / \mathrm{sq} \mathrm{m}$ to $+10 \mathrm{~W} / \mathrm{sq} \mathrm{m}$ when applying Eppley calibration factor and dome correction factor $=3.5$.

\subsubsection{Radiometer Calibration Facility Data Acquisition System Replacement (deferred to FY2008)}

The data acquisition system in the Radiometer Calibration Facility used for annual Broadband Outdoor Radiometer Calibration (BORCAL) activities is over ten years old and needs to be updated. NREL has recently replaced their BORCAL data acquisition system using internal funds. The SGP system should be a duplicate of the NREL system for software compatibility and performance assurance. 


\subsection{Carbon Dioxide Flux System $\left(\mathrm{CO}_{2} \mathrm{FLX}\right)$}

Mentor: Marc Fischer, Lawrence Berkeley National Laboratory

The $\mathrm{CO}_{2} \mathrm{FLX}$ instruments at 4,25 , and $60 \mathrm{~m}$ on the SGP-CF tower are operating nominally with the exception of the net radiometers. During December, the CNR-lite net radiometer was returned to Lawrence Berkeley National Laboratory for re-calibration. It appears that the data from the downwelling long wave channel on the CNR-1 continues to be incorrect.

\subsection{Carbon Monoxide System (CO)}

Mentor: Sébastien Biraud, Lawrence Berkeley National Laboratory

The CO system was operating nominally.

\section{$2.7 \quad \mathrm{CO}_{2}$ (Precision Gas) System (PGS)}

Mentor: Margaret Torn and Sebastien Biraud, Lawrence Berkeley National Laboratory

The PGS is operating nominally.

\subsection{Cimel Sun Photometer}

Mentor: None (external data provided by NASA AERONET)

Aerosol Robotic Network (AERONET) has confirmed that problems with the camel photometer (CSPHOT) identified at SGP (thanks to Christine Chiu) are due to errors in the Cimel firmware programming. This affects the new instrument deployed at Nauru as well as the instrument at SGP. AERONET will replace the EPROM in the SGP instrument after the problem is corrected by Cimel and verified by AERONET. The EPROM in the instrument at Nauru can be replaced during a subsequent RESET visit. This may delay the return of CSPHOTs to Barrow the AMF.

NSA (Barrow) - Removed in mid-October for annual recalibration. It will be re-installed in March after the sun rises again in Barrow. AERONET will upgrade this instrument to add a channel at $1640 \mathrm{~nm}$ at no $\underline{\text { cost to ARM. }}$.

SGP $(\mathrm{CF})$ - Removed in February and returned to AERONET to investigate internal programming problems. A loaner Cimel was furnished by AERONET until the problem can be corrected. AERONET will also upgrade the SGP instrument to add a channel at $1640 \mathrm{~nm}$ at no cost to ARM.

TWP (Nauru) - A new Cimel was installed in late November. The Cimel that had been at Nauru has been sent to AERONET for recalibration and upgrade to add a channel at $1640 \mathrm{~nm}$. It will then be sent to Germany where it will be swapped with the Cimel currently with the AMF.

AMF (Niamey) - Shut down in January at the conclusion of the AMF deployment in Niger. 


\subsubsection{Internet Data Transfer}

The transfer of CSPHOT data from the Cimel instrument to AERONET using geostationary operational environmental satellite or Meteosat will be replaced with an Internet data transfer to improve reliability of the transfer, to permit ACRF personnel to monitor the transfer, and to allow the raw data to be acquired, ingested, and archived for use by ARM Science Team members (ECO-00555).

December 2006 - Internet transfer of CSPHOT data to AEORNET has been initiated at TWP-Nauru and SGP sites.

\subsection{Disdrometer}

Mentor: Mary Jane Bartholomew, Brookhaven National Laboratory

Deployment of an optical rain gauge at SGP would benefit measurement of light rain conditions that the tipping bucket gauges have difficulty with. This would also benefit ARSCL processing, which currently uses the moisture detector on the microwave radiometer (MWR) at SGP-CF as a sensitive light rain detector.

\subsection{Energy Balance Bowen Ratio Station}

Mentor: David Cook, Argonne National Laboratory

In January, severe winter weather conditions across the SGP domain adversely affected many of the energy balance bowen ratio (EBBR) stations. This included frozen automatic exchange mechanisms (AEMs), wind speed sensors, and a broken net radiometer dome.

Vaisala no longer supports the combined temperature and relative humidity probes in the EBBR (2 per system) but does still offer recalibration services. Replacement probes are available from the EBBR manufacturer. The mentor has proposed that replacement of all 32 probes be phased in over 3 years. As the old probes are replaced they can be used as spares for the systems not yet upgraded to the new probes.

\subsection{Eddy Correlation Station}

Mentor: David Cook, Argonne National Laboratory

SGP - All eddy correlation (ECOR) stations are operating nominally with only a few weather-related gaps. Problems with the new optical isolators implemented to protect the ECOR computer serial ports during lightning have been traced to the serial driver chips in the infrared gas analyzers (IRGA). David is working with the IRGA manufacturer to correct the problem.

AMF - Shut down in January at the conclusion of the AMF deployment in Niger. 


\subsubsection{Add Wetness Sensors}

Periods of dew, frost, and precipitation often cause data from the $\mathrm{CO}_{2} / \mathrm{H}_{2} \mathrm{O}$ sensor and sonic anemometer to be incorrect. Adding a wetness indication would provide the data user with a more reliable source of information concerning this condition (ECO-00536).

January 2007 - Wetness sensor testing on an ECOR system similar to the ARM ECORs began at Argonne in mid-January.

\subsection{G-Band (183.3 GHz) Water Vapor Radiometer}

Mentor: Maria Cadeddu, Argonne National Laboratory

The GVR is operating nominally. GVR data are now available from the ARM Archive (nsagvrC1.b1). Varying levels of RFI are observed in all four channels. Software modifications have been implemented to permit hourly data ingest (rather than daily) in support of RHUBC.

\subsection{Global Positioning System (SuomiNet)}

Mentor: None (external data provided by SuomiNet/COSMIC)

SGP - Telecommunications problems at El Reno (E19) continue to affect data availability from the SuomiNet station. Wireless data communication equipment has been ordered for installation at El Reno (E19). All other SGP SuomiNet global positioning system (GPS) stations and their associated meteorological sensors are operating nominally.

TWP (Manus) - Operating nominally.

TWP (Nauru) - In November the GPS receiver at Nauru failed. The unit has been returned to the U.S. for warranty service. Following this repair, the GPS receivers at Manus and Darwin will be returned to have the defective component replaced prior to failure.

TWP (Darwin) - Operating nominally.

NSA (Barrow) - (System belongs to the University of Alaska at Fairbanks (UAF) and is installed at NOAA/CMDL site.) Operating nominally using a spare ARM met system.

NSA (Atqasuk) - In June 2006 University Navstar Consortium personnel installed a GPS receiver at Atqasuk for geodetic purposes. The spare ARM GPS meteorological system currently in use at Barrow will be connected to this receiver once the UAF met system is repaired and returned to Barrow, then the Atqasuk station will be incorporated into SuomiNet to provide precipitable water vapor data.

\subsection{In situ Aerosol Profiling}

Mentor: John Ogren and Betsy Andrews, NOAA/ESRL/GMD

There have been 682 IAP flights since the beginning of the program in March 2000 through 22 February 2007). 
The high (85\%) relative humidity nephelometer continued to have problems after being replaced in September. The instrument that was returned to the manuafacturer in September for diagnosis and repair of this problem has not yet been returned. Also, the engine pump that draws sample air through the optical instruments failed 21 December 2006 and was replaced on 26 January 2007. Data from the optifcal instruments is invalid during this period.

\subsection{InfraRed Thermometer}

Mentor: Vic Morris, Pacific Northwest National Laboratory

InfraRed Thermometers (IRTs) have been deployed at 12 SGP extended facilities (ECO-345), operating at $5 \mathrm{~Hz}$ sampling rate. IRTs are also part of the SKYRAD and GNDRAD systems at TWP, NSA, and AMF. These are currently sampled at $0.5 \mathrm{~Hz}$. Plans to increase the sampling rate of the SKYRAD IRTs to $5 \mathrm{~Hz}$ are in progress (ECO-00368).

The IRTs are operating nominally at all sites except SGP E13 and E19 where higher sky temperatures were measured than at other sites. For sky temperatures less than $-60^{\circ} \mathrm{C}$ the IRTs at SGP report higher sky temperatures than the AERI over the $10-\mu \mathrm{m}$ pass band of the IRT. An IRT and its enclosure were sent to the manufacturer for diagnosis. They did not find any problems with the design of the enclosure/mirror system and suggested that the influence of the mirror on the measured temperature be accounted for.

\subsection{Multi-Filter Rotating Shadowband Radiometer and Related Systems (MFR, GNDMFR, NIMFR)}

Mentor: Gary Hodges, NOAA/ESRL/GMDivision; John Schmelzer, Pacific Northwest National Laboratory

John Schmelzer has indicated he plans to retire in May.

SGP - 9 of 22 Extended Facilities do not have operational muti-filter rotating shadowband radiometers (MFRSRs).

NSA - MFRSRs, MFRs, and normal incidence multi-filter radiometers (NIMFRs) have been recalibrated and returned for re-installation at Barrow and Atqasuk.

TWP - Operating nominally.

AMF - Shut down in January at the conclusion of the AMF deployment in Niger.

Twice-per-day cleaning of the NIMFR at SGP has been initiated to eliminate the step-change in the measurements observed following the current once-per-day cleaning events. 


\subsubsection{Filter-Detectors}

ACRF has $\sim 50$ multi-filter radiometers deployed in a variety of configurations including the MFRSR, the downward-facing MFR, and the NIMFR. The 6 narrow band $(10 \mathrm{~nm})$ filter-detectors in almost all of these sensors have degraded over time and are in urgent need of replacement. Perkin-Elmer has manufactured custom-designed and custom-built filter-detector assemblies to meet ACRF specifications (ECO-00580).

STATUS - John Schmelzer is refurbishing and calibrating MFRSR sensor heads using the new filterdetectors at the rate of 3-4 per week. Three newly upgraded heads have been sent to SGP for installation with the new data loggers.

\subsubsection{Multi-Filter Rotating Shadowband Radiometer Calibration and Data Processing Improvements}

Problems with the calibration and data processing of the MFRSRs were revealed during the ALIVE campaign (ECO-00571). New calibration processing will be implemented. Old data will be reprocessed to apply corrections and the new processing algorithms.

STATUS - Discussions about establishing a MFRSR calibration facility at the SGP have been initiated.

\subsubsection{Data Logger Replacement}

The proprietary data loggers supplied with the MFRSRs and related instruments are to be replaced with Campbell Scientific CR1000 data loggers. This will permit them to be more easily maintained. It will also permit modifications to the operation of the instruments and data acquisition to be easily implemented (ECO-00350).

STATUS - In January John Schmelzer sent three new data loggers and related equipment to SGP. In February the first of these was installed at the E13 site. These data are currently being collected; ingest development is nearly complete. Once the first installation has been verified subsequent installations will follow.

\subsection{Millimeter Cloud Radar}

Mentor: Kevin Widener, Pacific Northwest National Laboratory; Karen Johnson, Brookhaven National Laboratory

NSA/C1 - In late January-early February Kevin traveled to Barrow to reinstall the repaired Traveling Wave Tube Amplifier (TWTA) and recalibrate the radar. The system has been restored to full operation.

$\mathrm{SGP} / \mathrm{C} 1$ - In December the millimeter wave cloud radar (MMCR) started to experience intermittent traveling wave tube (TWT) helix voltage faults. In January the problems worsened (67\% uptime) so the TWTA was removed and sent to ASE for diagnosis and repair. ASE found no problems with the TWTA, which was returned and reinstalled in February. Periodic faults continue to occur. 
TWP/C1 (Manus) - 88\% up time in January. The power output of this system continues to decline. When our next order of new TWTs arrives in March or April one will be sent to ASE to repair the old TWTA from Nauru, which will then be sent to Manus for replacement.

TWP/C2 (Nauru) - 100\% up time in January.

TWP/C3 (Darwin) - 100\% up time in January.

\subsubsection{MMCR Processor Upgrades}

(ECO-00283) Spectral imaging problems with the PIRAQ-III processor have been resolved at Darwin by installing newly developed filter coefficients. The spare PIRAQ-III processor will be installed in the MMCR at Darwin to replace the PIRAQ-III that failed. The NSA (Barrow) upgrade will be delayed until the failed processor is repaired or another spare is purchased.

\subsubsection{Add Polarization at Barrow}

(ECO-0052) September 2006 - The orthomode transducer has been received. Because the PIRAQ processor does not support polarization, the installation of the orthomode transducer at Barrow is on hold until the next processor upgrade.

\subsubsection{Spare Traveling Wave Tubes}

New TWT will be ordered to replace the TWTs originally delivered with the MMCRs, which are well beyond their rated lifetime and are beginning to fail (ECO-00425).

STATUS - The new TWT delivered in 2005 was installed in the Darwin MMCR just prior to TW-ICE. Three more TWTs were received in 2006 and have been installed at SGP, Nauru, and Barrow. Two additional TWTs have been ordered to replace the failing TWT at Manus and to have a spare. These are scheduled for delivery in March/April. Because the TWTs only have a 2-year lifetime, at least one more TWT needs to be ordered this year to permit the TWT at Darwin to be replaced in November 2007.

\subsubsection{Millimeter Wave Cloud Radar Spectra Processing}

Spectra files produced by the upgraded MMCRs (C40 or PIRAQ-III processors) range from 8 to 15 Gigabytes per day. Algorithms for eliminating clear-sky periods and compressing the files need to be developed and implemented locally (ECO-00391).

January 2007 - The compression algorithms have been implemented at SGP.

\subsubsection{Refurbish Millimeter Wave Cloud Radar Antennas}

Beginning in 2007, over a three-year period the MMCR antennas will be refurbished and characterized on an antenna range (ECO-00551). 
January 2007 - The antenna is complete and the contract for the new feed and sub-reflector has been placed. Once these are complete, they will be installed on the antenna reflector and calibrated. The Barrow MMCR antenna will most likely be refurbished first to avoid impacting planned IOPs at SGP.

\subsubsection{Radome or Radome Dryer}

The detrimental effect on the data of standing water on the current fabric radome has prompted the pursuit of a more satisfactory solution. Unfortunately discussions with potential suppliers have not been fruitful. This taskis currently on hold (EC-00275).

\subsection{Micro-Pulse Lidar}

Mentor: Rich Coulter, Argonne National Laboratory

New, polarized micropulse lidars (MPLs) are now operating at SGP, TWP (Darwin, Nauru, Manus), and NSA (Barrow). The old MPL with the AMF at Niamey has been shut down following the conclusion of the Niger deployment. A new MPL will replace it for the deployment at Heselbach, Germany.

SGP - Good data to greater than $15 \mathrm{~km}$ is normal during nighttime and 10-15 km during daytime with no additional averaging beyond the 3 second averaging time presently in use by the instrument itself.

NSA - The system is again producing good data following replacement of the detector by NSA technicians in January.

TWP - The new MPL at Nauru has been working well. A replacement detector has been sent to Darwin to resolve problems manifesting as thin, false cloud layers near $10 \mathrm{~km}$ and $20 \mathrm{~km}$.

A value-added processing (VAP) has been developed to produce a file with separated polarization states, averaged to 30 seconds. This will appear similar to the present MPL data in terms of averaging time. It will have two data streams, one for circular polarization and a second for cross polarization.

Rich Coulter and Tim Martin have developed and tested a means to automatically restart the new MPLs. This has not yet been implemented because some of the laser power supplies need to have their firmware updated to support external control.

\subsection{Microwave Radiometer}

\section{Mentor: Maria Cadeddu, Argonne National Laboratory}

SGP - Six MWRs were compared during October-November 2006: serial numbers 04, 10 (both from $\mathrm{SGP} / \mathrm{CF}), 11$ (SGP/B1), 12 (SGP/B5), 18 (SGP/B6), and 21 (NSA/C2). Differences of as much as $0.7 \mathrm{~K}$ in brightness temperatures at $23.8 \mathrm{GHz}$ (corresponding to $\sim 0.5 \mathrm{~mm}$ PWV) were observed between radiometers. Shipment of several of these radiometers to Radiometrics for diagnosis and repair has been delayed due to funding limitations under the Continuing Resolution.

AMF (Niamey) - Shut down following the conclusion of the Niger deployment. 
NSA/C1 (Barrow) - Comparisons of the MWR wet window flag with the MWRP wet window flag and tower precipitation sensor revealed that the threshold for indicating the presence of liquid water required adjustment (for both MWR and MWRP).

NSA/C2 (Atqasuk) - Not in service. In October this radiometer was sent to the SGP central facility for inclusion in the MWR Inter-comparison IOP.

SGP/B1 (Hillsboro) - Not in service. In October this radiometer was sent to the SGP central facility for inclusion in the MWR Inter-comparison IOP.

SGP/B4 (Vici) - No radiometer installed. In December 2005 the radiometer at Vici was sent to Darwin as a replacement for one damaged by lighting.

SGP/B5 (Morris) - Not in service. In October this radiometer was sent to the SGP central facility for inclusion in the MWR Inter-comparison IOP.

SGP/B6 (Purcell) - In October this radiometer was sent to the SGP central facility for inclusion in the MWR Inter-comparison IOP. In December this radiometer was sent to Manus to replace the failed MWR there.

TWP/C1 (Manus) - This radiometer (\#15) experienced a failure in October. A replacement circuit card failed to restore operation. A replacement radiometer from SGP (\#18 formerly at SGP/B6) was shipped in December. Radiometer \#15 required extensive (and expensive) repairs after ten years on Manus Island. It will be compared with MWRs at SGP prior to returning to service.

TWP/C2 (Nauru) - A replacement was installed in late November. The MWR has been returned to Radiometrics for service.

TWP/C3 (Darwin) - Operating nominally.

\subsubsection{Unify Microwave Radiometer Connectors}

The Impulse connectors on the 3 MWRs at the TWP sites make it difficult to substitute a spare MWR in case of a failure, as occurred in Darwin prior to TWP-ICE due to a lightning strike. Accordingly, the Impulse connectors are being replaced with the standard connectors used on all other MWRs.

STATUS - The connectors on MWR \#15, formerly on Manus, were replaced when the instrument was repaired. MWR \#16, formerly on Nauru, will be upgraded in February/March.

\subsection{Microwave Radiometer Profiller}

Mentor: Maria Cadeddu, Argonne National Laboratory

NSA (Barrow) - Data for this month are generally good and continuous. The 2-channel PWV retrievals are in good agreement with the MWR. The retrieved 2-channel LWP is consistent with the MWR retrievals, however the 6 -channel retrieval shows a progressive drift towards negative values. (See 
D070221.1) Because the drift is not observed in the two-channel retrieval it is likely that there is a drift in the 51-GHz channel, which requires recalibration with liquid nitrogen $\left(\mathrm{LN}_{2}\right) . \mathrm{A} \mathrm{LN}_{2}$ calibration is scheduled for late February.

AMF (Niamey) - Shut down following the conclusion of the Niger deployment.

\subsection{Narrow Field of View Radiometer (NFOV)}

Mentor: None

The 2-channel Narrow Field of View (NFOV) radiometer has been removed from service at SGP and sent to NASA Goddard Space Flight Center (GSFC) for calibration using the AERONET facilities. It will be deployed with the AMF in Germany.

Recalibration of the 2-channel NFOV at NASA GSFC resulted in good agreement with a Cimel sunphotometer at $940 \mathrm{~nm}$ and $673 \mathrm{~nm}$. (A 5\% bias was observed at low radiances at $940 \mathrm{~nm}$, but the bias disappeared at higher radiance values.) The NFOV will be returned to SGP for shipment to Germany.

With the advent of the 2-channel NFOV, there no longer appears to be any interest in the 1-channel NFOV. Consequently it has been suggested that the 1-channel NFOV be retired.

\subsection{Raman Lidar}

\section{Mentor: Rob Newsom, Pacific Northwest National Laboratory}

Rob Newsom has succeeded Diana Petty as the instrument mentor for the Raman Lidar.

Analysis of the signal strength in the wide field of view and NFOV Nitrogen channels suggests that the signal strengths have declined significantly since 2004. The decrease is evident in the peak signals as well as in the background signals which rules out degradation of the laser as a reason. One possible cause for the loss of sensitivity could be a degradation of the mirrors in the telescope (which was the cause of the loss of sensitivity in 2002-2003). A second possible cause for the loss of sensitivity could be that the transmission of the interference filters has degraded. The filter manufacturer does not believe that this could have occurred, but is willing to measure the transmission of one or more of the interference filters for free to confirm or reject possible degradation in the transmission characteristics of the interference filters.

No water vapor mixing ratio data are available from the Raman lidar since early 2004 because of difficulties encountered in combining the analog detection (AD) and photon counting (PC) signals from the Licel electronics during the daytime. To help resolve this problem, a photomultiplier tube, base, and housing have been sent to Licel Electronics in Germany for testing with their equipment. A teleconference to discuss the problems encountered in merging the PC and AD signals, and potential solutions, was held on 16 February. Participants included Bernd Mielke (Licel), David Turner, Diana Petty, Rob Newsom, John Goldsmith, Rich Ferrare, Connor Flynn, and Zhien Wang. One outcome of the teleconference was the decision to proceed to process the nighttime data, which do not seem to be affected by the problem. 
Temperature profile retrievals are adversely affected by high solar background noise during the daytime. This is believed to be due to out-of-band leakage into the rotational Raman channel. Adding a wider band filter to block the leakage is being considered.

\subsubsection{Add Automatic Alignment System}

Due to small thermal gradients in the laser and the lidar enclosure, the alignment of laser beam in the detectors' field-of-view (FOV) changes with time, which can affect the data quality, sometimes substantially. To address this operationally, the laser beam is swept through the detectors' FOV using a pico-motor controlled steering mirror to find the optimal location. This "alignment tweak" is scheduled to occur every 3 hours. Accounting for the potentially 3-hourly changes in alignments is the single largest uncertainty in the data processing codes. It affects all measurements, but the aerosol extinction measurements and the temperature profiles seem to be the most sensitive. Licel has recently developed a new product that permits the alignment of the lidar to be actively maintained (ECO-00586). The Licel alignment sensor was delivered in September.

January 2007 - Licel has recently made improvements to the alignment sensor and has exchanged the original sensor for a new one. Insallation has been rescheduled for April 2007.

\subsection{Rotating Shadowband Spectrometer}

Mentor: Peter Kiedron, NOAA/ESRL/GMD

The rotating shadowband spectroradiometer (RSS) is operating nominally. Field calibrations are nominal. Automatic processing of calibration data is under development by Peter Kiedron and Jim Schlemmer.

\subsection{Radar Wind Profiler - $915 \mathrm{MHz}$}

Mentor: Rich Coulter, Argonne National Laboratory

SGP - Currently, all systems at SGP are operating nominally. The SGP/C1 (central facility) and SGP/I3 (Meeker) have had the digital receiver upgrades successfully installed. The problem with RASS data being "reflected" at large range gates has mysteriously improved recently.

NSA - System crashes frequently. Maybe the upgraded hardware, LAPXM software, and a new computer should help resolve this problem.

AMF (Niamey) - Returned to Vaisala following the conclusion of the AMF deployment to Niger. (This $915 \mathrm{MHz}$ rental system will be replaced by the new $1290 \mathrm{MHz}$ system in Germany.) 


\subsubsection{Upgrade to Digital Receivers}

The four $915 \mathrm{MHz}$ RWPs at the SGP are now 9-13 years old and are exhibiting increasingly frequent, strange, and expensive-to-repair failures. This may pose problems for Cloud Land Surface Interaction Campaign (CLASIC), scheduled in 2007. Due to the age of these systems, parts are increasingly difficult to obtain (Vaisala no longer has exact replacements for some items; the available parts must be modified for use in our systems). Vaisala offers an upgrade for these systems that will replace the present interface, receiver and computer (including DSP board) with new components and will include the latest version of LAPXM, the operating system. The systems at SGP/CF and SGP/I3 have been upgraded. The systems at SGP/I2, SGP/I3, and NSA/C1 will be upgraded in 2007 (ECO00567).

\subsection{Radar Wind Profiler - $\mathbf{5 0} \mathbf{~ M H z}$}

Mentor: Rich Coulter, Argonne National Laboratory

This system has been out of service for over a year.

In January 2006 the $50 \mathrm{MHz}$ RWP at the SGP ceased transmitting. The transmitter was returned to ATRAD in Australia for diagnosis and repair. After reinstalling the transmitter the output power was still zero. The power tube was replaced but the output power is still zero. Vaisala has loaned SGP test equipment to help diagnose the problem.

\subsection{Soil Water and Temperature System}

Mentor: John Harris, University of Oklahoma

The severe winter weather across the SGP domain in January caused near-surface soil measurements to be incorrect at many sites due to icing effects. Some sensors have failed at some sites, but at least one sensor is working at each level at each site. (Sites with two failed sensors at the same level have already been replaced. See below.)

\subsubsection{Replace In-Ground Sensor Arrays}

New redundant sensor arrays will be installed at all SGP EF sites. These will be installed in a phased manner: 5 sites per year over the 4 years beginning in 2005 with the sites having multiple failed sensors given highest priority. After the soil recovers from the installation process in 6-12 months, the new sensor array will be connected to the existing SWATS data acquisition system in place of the old sensor array (ECO-00493).

STATUS - In 2006, new sensor arrays were installed at E13, E19, and E24. Though initially planned, no new sensor array was installed at Cyril (EF-24) due to a gypsum outcropping. The original sensor array had been installed in a "hole" in the gypsum filled with soil. There was no other such area of soil and it is unlikely that soil moisture measurements at the site would be representative of the actual conditions of the surrounding area. The new sensor arrays will replace the original arrays (i.e., be connected to the data loggers) as soon as sufficient precipitation has "healed" the soil. The mentor believes this will happen within the next two rain events. The next round of sensor array installation is planned for April, but could be delayed until May depending on weather conditions. 


\title{
2.27 Shortwave Spectrometer (SWS)
}

\author{
Mentor: Scott Kittelman, University of Colorado
}

On January 11, 2006, the Shortwave Spectrometer was reinstalled and calibrated at the Southern Great Plains Central Facility by Warren Gore and Tony Trias from NASA Ames. Data ingest has been suspended until modifications needed to accommodate revised SWS calibration processing and settings are completed.

\subsection{Surface Meteorological Instrumentation (SMET, SMOS, SURTHREF, THWAPS, MET, ORG, PWS)}

Mentor: Mike Ritsche, Argonne National Laboratory

SGP (SMOS) - In January severe winter weather conditions caused communication outages and affected wind speed sensors at several sites. Installation of new Vaisala temperature/relative humidity probes has begun (BCR 1298) to replace old probes no longer supported by Vaisala (EWO-11056).

TWP (SMET, ORG) - All systems are operating nominally. The barometer at Nauru failed in early December and was replaced on 23 January.

NSA (METTWR) - Icing continues to be a problem with the wind direction sensors, which do not have a heater in the vane. Ice accumulates on the vane and causes the direction measurements to become sluggish (standard deviations at or near 0). This problem is worse in the transition months when the snow is much wetter and is more likely to stick to the vane.

AMF (MET, ORG) - Shut down following the conclusion of the AMF deployment to Niger.

\subsubsection{Develop Dynamic Rain Gauge Calibration Facility}

The tipping bucket rain gauges at the $15 \mathrm{SGP} / \mathrm{EF}$ sites with SMOS are currently calibrated using only a "static" calibration: a measured volume of water is poured into the gauge and the number of bucket tips is checked to ensure they correspond. In reality, as the rain rate increases and the bucket tips more frequently some rain is not collected. The purpose of the dynamic calibration is to determine the correction factor as a function of rain rate to account for this behavior (ECO-00495).

STATUS - Problems with the software developed by the University of Iowa have been largely resolved.

\subsubsection{Upgrade T/RH Probes and Wind Sensors for NSA Met Systems}

Ice develops on the wind vanes, cup anemoneters, and aspirator inlets for the temperature and relative humidity sensors, which clog and affect the data quality. To alleviate these problems the mentor has proposed to replace the wind speed and direction sensors at NSA (both Barrow and Atqasuk) with sonic anemometers, and to replace the temperature and relative humidity probes with new, heated probes designed to operate in cold environments (ECO-00595).

STATUS - Deferred until higher priority instrument procurements are completed. 


\title{
2.29 Tandem Differential Mobility Analyzer
}

\author{
Mentor: Don Collins, Texas A\&M University
}

Data from the Tandem Differential Mobility Analyzer (TDMA) are currently acquired and processed by Don Collins. Processed data are then delivered to ACRF on a monthly basis and stored in the IOP area of the Archive as "beta-data." An ingest is being developed to produce netcdf files for inclusion in the main Archive (ECO-587).

\subsection{Hot Plate Total Precipitation Sensor (TPS)}

Mentor: Mark Ivey, Sandia National Laboratory

This is a new sensor developed by Roy Rasmussen at National Center for Atmospheric Research and commercialized by Yankee Environmental Systems (YES). The instrument has been installed in close proximity to a World Meteorological Organization (WMO)-standard double fence inter-comparison reference shield and Geonor weighing precipitation gauge deployed by the NOAA Climate Reference Network (CRN). If the first sensor compares well with the CRN measurements, a second TPS could be acquired for mounting on the 40-m tower at Barrow to discriminate between blowing and falling snow. Acquisition of a TPS for Atqasuk may also be desirable if the first unit proves successful at Barrow.

Data are available from the ARM Archive (nsatpsC1.b1). Problems with animals chewing through the fiber optic cable to the TPS will be resolved by implementing wireless data communication to the TPS. In February, the TPS sensor was relocated to the lower level (former WSI level) of the User Facility in Barrow. This move allows data to flow and instrument assessment to continue until the wireless communications equipment is acquired to replace the vulnerable fiber link.

\subsection{Total Sky Imager}

Mentor: Vic Morris, Pacific Northwest National Laboratory

SGP - Operating nominally.

TWP - TSIs at Nauru and Darwin are operating nominally. The Manus TSI was repaired in Darwin and returned to service on 30 January, however the images appear hazy.

NSA - The instrument has been removed until the sun is $5^{\circ}$ above the horizon in February.

AMF - Shut down in January following the conclusion of the AMF deployment to Niger.

New, improved mirror controllers are being developed by Ray Edwards at Brookhaven National Laboratory.

\subsection{Meteorological Tower Systems}

Mentor: David Cook, Argonne National Laboratory

60-m tower at SGP C1 (central facility) - nominal operation.

21-m tower at SGP E21 (Okmulgee) - nominal operation. 
40-m tower at NSA C1 (Barrow) - problems due to ice formation on temperature/humidity sensors and on the wind direction vanes continue. Replacement of these sensors with sonic anemometers and heated temperature/humidity probes has been proposed (ECO-00595).

David has begun planning for annual tower maintenance at SGP and NSA.

\subsection{Vaisala Ceilmeter}

Mentor: Vic Morris, Pacific Northwest National Laboratory

Electronic ringing in the backscatter plot is visible at SGP-B5 (Morris, OK), but this does not affect the instrument's ability to detect clouds.

In January, the standard unit at Darwin was replaced with a ceilometer having a "tropical" window. Later in January the standard unit was reinstalled at Darwin and the tropical unit was sent to Nauru. The ceilometer used in the Nauru Island Effect Study was returned to Vaisala for repair.

\subsection{W-band (95 GHz) Atmospheric Radiation Measurement Program Cloud Radar}

Mentor: Kevin Widener, Pacific Northwest National Laboratory

SGP - Operating nominally; $100 \%$ up time in January.

AMF (Niamey) - A $15 \mathrm{GHz}$ oscillator failed in December. The radar has been shipped to ProSensing for warranty repair then will be reinstalled at the AMF site in Germany. 


\section{Future Instrumentation Planning}

In this section instrumentation that have been proposed for future acquisition and discussed by the Science Team Working Groups - but not yet approved for purchase - are presented along with any status information.

Acquisition of all new instrumentation is on hold pending the prioritization of instrument needs by the ARM Science Team Executive Committee and the finalization of the ACRF budget.

\subsection{Atmospheric Radiation Measurement Program Volume-Imaging Array}

The ARM Volume-Imaging Array (AVA) is a proposed radar system to be deployed at the ARM SGP site to address the ARM program's need of mapping 3D cloud and precipitation structures at short to medium ranges (i.e., 20-75 km). The AVA system will provide time-resolved 3D precipitation fields, domain-averaged rainfall rate, cloud coverage throughout a volume, cloud-top heights, hydrometeor phase information (using polarization), horizontal and vertical variability of clouds and precipitation, and low-level convergence and divergence using dual-Doppler techniques. Principal elements of the AVA proposal prepared by Pavlos Kolias include:

- Three networked scanning radars arranged in a triangle with $20-30 \mathrm{~km}$ legs: one operating at $35 \mathrm{GHz}$ (same 8.6-mm wavelength as the MMCR) and capable of scanning the vertical region probed by the current MMCR, and two radars operating at $9.4 \mathrm{GHz}$ (3.2-cm wavelength, so-called "X-band"). All three radars will be transportable, scanning, polarimetric and Doppler.

- Development of a useful 3D cloud VAP similar to the existing ARSCL but on a regular 3D grid.

- Development of an "AVA Simulator." Patterned after the well-known International Satellite Cloud Climatology Program Simulator, the AVA Simulator will perform forward simulations of radar observables, using as input large-eddy simulation model and cloud-resolving model outputs of cloud properties together with the characteristics of the AVA radars. The results will be used to develop and optimize volumetric radar scanning strategies, develop and evaluate inverse retrieval techniques, and develop prototype 3D ARSCL-like VAPs for the ARM community.

- A collaborative effort with the Center for Interdisciplinary Remotely-Piloted Aircraft Studies (CIRPAS) to deploy the CIRPAS 9.4-GHz phased-array radar at the ARM SGP site every year for 1-2 months of continuous observations.

STATUS - Consideration of the AVA, as such, has been deferred until 2008 when simulations have been carried out to demonstrate its capabilities and further refine its requirements. 


\subsection{Portable Raman Lidar}

Leosphere http://www.lidar.fr/ offers a portable MPL-type lidar that can be augmented with Raman capability. Raymetrics http://www.raymetrics.gr/(sold by Kipp \& Zonen) also offers a Raman Lidar. Both concerns have been invited to deploy their systems at SGP for comparison with the SGP Raman Lidar and MPL. Leosphere is planning to deploy a lidar at the SGP in late October.

October 2006 - Iwona Stachlewska of Leosphere deployed their non-Raman EZ Lidar at the SGP on 19 October for comparison with the ARM MPL system. Leosphere expects to have a commercial Raman system available in mid-to-late 2007. Raymetrics will not be able to furnish a demonstration Raman lidar system.

STATUS - Clarification of the scientific requirements for a portable Raman lidar is necessary before proceeding.

\subsection{Absolute Scanning Radiometer}

To provide an absolute IR flux reference, which could be used to calibrate the Eppley PIRs, Ells Dutton has suggested that ARM develop an Absolute Scanning Radiometer (ASR). This instrument would be functionally equivalent to an ASR developed by Rolf Philipona for the WMO. This instrument would not be used for routine data acquisition, but instead would provide a calibration reference. As such it would participate in WMO inter-comparisons at Davos, Switzerland every five years. Although a SBIR solicitation for an ASR was issued circa 2000, no successful proposals were received. Ells Dutton, Tom Stoffel, and Joe Michalsky are planning to develop a specification so that ACRF may send out a request for proposals to identify interest and cost for such an instrument.

STATUS - In December 2006 a description of the desired instrument capabilities was published in Fed Biz Ops (solicitation number 111506). Based on the published description, Rough Order of Magnitude cost estimates have been received from several interested organizations.

\subsection{High-Resolution Oxygen A-Band and Water-Band Spectrometer}

Qilong Min has submitted a proposal to build an A-band spectrometer for ARM following his presentation to the Cloud Properties working group in October 2004 on this topic. The 3-year proposal and budget were sent out for technical reviews. The technical reviews, along with the proposal and budget, were then provided to the Science Team Executive Committee. The Science Team Executive Committee directed Qilong to present his plan and budget to the Cloud Properties working group at their November 2005 meeting for prioritization. Qilong presented a revised work plan (water-band/cloud phase components removed) and has submitted a revised budget.

\subsection{Rotating Shadowband Spectrometer Overhaul}

Peter Kiedron has demonstrated that the RSS built by YES is capable of providing valuable measurements of direct, diffuse, and global spectral irradiance. Peter has also identified problems with the RSS that affect the stability of its calibration and the linearity of its response. Peter has recommended that the RSS be removed from service and sent to him at SUNY-Albany for a complete overhaul. 


\subsection{Add 1.6 $\mu \mathrm{m}$ Channel to Multi-Filter Rotating Shadowband Radiometer and Narrow Field of View}

Alexander Marshak has recommended that ARM support the development of a NFOV radiometer at $1.6 \mu \mathrm{m}$ to permit the retrieval of droplet size distribution. Andy Lacis and colleagues have suggested a $1.6 \mu \mathrm{m}$ channel be substituted for the unfiltered (broadband) channel in the MFRSR. A cursory examination of Perkin-Elmer's web pages reveals Indium-Galium-Arsinide (InGaAs) detectors are available that operate in this spectral region. This would require a development effort.

July 2006 - Two InGaAs detectors and two $1.6 \mu \mathrm{m}$ filters have been purchased to determine the feasibility of implementing them in the MFRSR and/or NFOV. In the MFRSR this filter-detector would replace the unfiltered (broadband) channel. Because the unfiltered channel is now being used in a broadband radiometer best estimate VAP for quality checking purposes, only a limited number of MFRSRs would be modified to accept a $1.6 \mu \mathrm{m}$ channel.

\subsection{Aerosol Particle Sizing Spectrometer to Replace Optical Particle Counter at Southern Great Plains}

John Ogren has suggested replacing the aging Optical Particle Counter included in the SGP AOS with a new Aerosol Particle Sizing Spectrometer to be integrated into the existing TDMA.

\subsection{Future Microwave Radiometers}

The 2-channel MWRs range between 6-13 years old. They are no longer being manufactured; Radiometrics has replaced them with an instrument that sequentially tunes to 5 frequencies in the 22-30 GHz range. Although Radiometrics continues to support the MWRs, it is useful to begin considering replacements for these instruments. Although $5 \mathrm{~K}$-band channels may provide more robust retrievals than 2 channels, RPG offers a comparably priced 3-channel radiometer $(23.8,31.4,90.0 \mathrm{GHz})$ that could also be considered because it increases the sensitivity to thin liquid water clouds. It is also desirable to acquire a final, "production" version of the $183 \mathrm{GHz}$ microwave radiometer developed by ProSensing under a U.S. Department of Energy SBIR Phase II award and deployed at Barrow since April 2005.

\subsection{Modified Muti-Filter Rotating Shadowband Radiometer for Liquid Water Path}

Qilong Min has proposed to modify the existing MFRSRs to permit him to retrieve liquid water path. Software modifications would be required to position the shadow band at several additional angles near the solar disk; modifications to the shadow band would be needed to either narrow it or increase its distance from the diffuser. A narrower diffuser (and modification to the sensor head) and an improved stepper motor and motor controller have also been proposed. A first phase might utilize a Rotating Shadowband Radiometer loaned to Min from Brookhaven National Laboratory. 


\subsection{Infrared Thermometers for the Southern Great Plains Extended Facility Sites}

Six IRTs were purchased in FY 2004, 9 additional IRTs were purchased in FY 2005. Some of these have been deployed with the AMF. Twelve SGP EF sites are currently equipped with IRTs; 10 additional IRTs would be needed to permit an IRT to be deployed at all 22 SGP extended facilities. 


\section{Small Business Innovation Research}

The DOE SBIR web page is at http:/www.er.doe.gov/sbir/

\subsection{Eye-Safe Ultraviolet Backscatter Lidar for Detection of Sub-visual Cirrus (FY 2006)}

Based on recommendations from the 2004 Cloud Properties working group meeting, this subtopic was substituted for the A-band spectrometer subtopic. Connor Flynn is the technical contact. Phase I funding was awarded to Aculight Corporation: "Eye-Safe ultraviolet Backscatter Lidar for Detection of SubVisual Cirrus" http://www.science.doe.gov/sbir/awards abstracts/sbirsttr/cycle24/phase1/039.htm

and to Physical Sciences, Inc.: "Field-Worthy ultraviolet Backscatter Lidar for Cirrus Studies." http://www.science.doe.gov/sbir/awards abstracts/sbirsttr/cycle24/phase1/044.htm

\subsection{Instrumentation for Remotely Sensing Aerosol Optical Properties - Aerosol Phase Function (FY 2006)}

Based on recommendations from the Aerosol working group, this subtopic was added to the aerosol measurements subtopic. Phase I funding was awarded to Aerodyne Research, Inc.: "CAPS-Based Particle Single Scattering Albedo Monitor."

http://www.science.doe.gov/sbir/awards abstracts/sbirsttr/cycle24/phase1/040.htm

\subsection{Unmanned Aerospace Vehicle-Suitable Cloud Radar (FY 2006)}

Phase I funding was awarded to ProSensing, Inc: "High-Power, Pod-Mounted W-band Cloud Radar for Unmanned Aerospace Vehicles (UAV)."

http://www.science.doe.gov/sbir/awards_abstracts/sbirsttr/cycle24/phase1/045.htm

\subsection{Radiometer Radiosonde (FY 2006 National Science Foundation Solicitation)}

The objective is to obtain a radiosonde with an onboard radiometer suitable for accounting for the radiative heating of the temperature sensor in the upper atmosphere. This is potentially interesting to ARM as a means for directly measuring the heating rate profile. Global Aerospace was awarded Phase I funding:

http://www.nsf.gov/awardsearch/showAward.do?AwardNumber=0539943

July 2006 - Matt Heun of Global Aerospace inquired about ARM's requirements for heating rate profile measurements. The BBHRP focus group provided their requirements to Matt. Matt and his colleagues have determined that, within the context of their current NSF SBIR project, they cannot control the tilt of the radiometers sufficiently to achieve the accuracy requirements provided by ARM; however, this could become the subject of a future DOE SBIR subtopic. Global Aerospace representatives have been invited at attend the ARM Radiative Heating Profile Workshop being organized by Warren Wiscombe. 


\subsection{In situ Measurement of Cloud Properties with Large Sample Volumes (FY 2007)}

Warren Wiscombe contributed the following sub-topic and will be the technical contact.

The DOE ARM Program was formed to study the climatic effects of clouds. These effects, particularly how clouds respond to climate change (the so-called "cloud feedback" problem), are large yet poorly understood from both a measurement and modeling point of view (cf. Stephens 2005). Currently, there is a huge gap in spatial scale between in situ measurements of cloud properties, typically from aircraft and balloons whose instruments have sample volumes on the order of cubic centimeters, and remote sensing retrievals of cloud properties, which have sample volumes ranging from tens of cubic meters (radar and lidar) to thousands of cubic meters (satellites). Most acute is the fact that in situ measurements at a particular point give no information on the vertical distribution above and below that point, while active remote sensing retrievals typically give instantaneous vertically-resolved information. Since clouds are inhomogeneous down to centimeter scales, there is a complete lack of comparability between in situ measurements and remote retrievals; simple assumptions of homogeneity to scale up the in situ measurements are certainly false. Clouds also evolve considerably in the course of a minute, and thus methods, which are slow in time (such as a balloon ascending, or an aircraft ascending or descending) fail to capture the instantaneous state which remote sensing sees. Thus, there is a great need for in situ measurements which have fast vertical reach and much larger sample volumes, ranging from cubic meters to hundreds of cubic meters, in order to allow meaningful comparisons with surface and satellite retrievals of cloud properties. Without confidence in those surface and satellite retrievals, which are our only way to extend our reach to the whole planet, it is impossible to make progression key global change issues concerning cloud feedbacks on global warming.

Therefore, grant applications are sought to develop instruments to measure cloud properties in situ, for scales ranging from cubic meters to hundreds of cubic meters, with particular emphasis on fast vertical profiling above and below the in situ platform. (The platform need not be a traditional aircraft or balloon; instruments for small UAVs, kites, gliders, and tethered balloons will also be considered.) An example of such an instrument can be seen in Evans et al. (2003). Measurements of the following cloud properties are particularly wanted, in order of decreasing priority for cloud-climate applications: (a) extinction coefficient at one or more wavelengths in the solar spectrum away from strong water vapor absorption bands; (b) total water content (liquid plus ice); (c) liquid and ice water content separately; (d) effective radius, defined as the ratio of the $3^{\text {rd }}$ to the $2^{\text {nd }}$ moment of the drop size distribution; (e) absorption coefficient or single-scattering albedo at one or more wavelengths in the solar spectrum away from strong water vapor absorption bands; (f) the scattering phase function for ice clouds; (g) the drizzle and precipitation fraction of the total condensed water content; (h) the supersaturation; (i) the dispersion, a measure of the width of the drop size distribution.

Stephens, G. 2005. "Cloud feedbacks in the climate system: A critical review." Journal of Climate 18:237-273.

Evans, KF. 2003. "In situ cloud sensing with multiple scattering lidar: Simulations anddemonstration." Journal of Atmospheric and Oceanic Technology 20:1505-1522. 